\title{
CONGENITAL ANATOMICAL MALFORMATION AT BIRTH IN WESTERN REGIONAL HOSPITAL, POKHARA, NEPAL
}

\author{
Sharma I. ${ }^{1}$, Rijal B.T. ${ }^{2}$, Thapa S.B. ${ }^{1}$, Poudel I. ${ }^{3}$
}

\section{ABSTRACT}

BACKGROUND: Congenital anomalies are any abnormality present at birth, either structural or functional, which may have been inherited genetically, acquired during gestation, or inflicted during parturition. There has not been much studies related to the congenital anomalies in Nepal.

METHODOLOGY: One year hospital based review study was conducted to find out the incidence, magnitude of congenital malformation and to know the specific involvement of anatomical structures among babies born at Western Regional Hospital, Pokhara, Nepal.

RESULTS: Of 10013 deliveries during the period of 1 year, total number of live birth was $98.82 \%$ (9895). Out of 9895 of total live births with any form of conginital anomolies was found amongst $0.42 \%$ (42) children, congenital anomalies were ranging from minor to major, single to multiple systems. Musculoskeletal anomalies accounted for the maximum of $57.1 \%$ followed by genitourinary anomaly $14.3 \%$. Nervous system anomaly was seen in $11.9 \%$ and few cases of gastrointestinal system anomaly and anomalies of the sense organs.

CONCLUSION: Incidence of congenital anatomical malformations at birth at Western Regional Hospital, Pokhara was found to be $0.42 \%$.

KEY WORDS: Birth defects, Congenital malformations, Anatomical structures

1. Lecturer, Faculty of Public Health, Pokhara University, Lekhnath-12, Kaski, Nepal

2. Student, Bachelor in Public Health, Pokhara University, Lekhnath-12 Kaski, Nepal

3. Student, Masters in Hospital Administration, Padmashree College of Hospital Administration, Banglore, India

\section{For Correspondence}

Mr. Ishor Sharma, M.P.H.,

Lecturer,

Faculty of Public Health,

Pokhara University, Nepal

E-mail: sharmaishor@yahoo.com 


\section{INTRODUCTION}

Congenital anomaly is defined as any abnormality present at birth, either structural or functional, which may have been inherited genetically, acquired during gestation, or inflicted during parturition. ${ }^{1}$ The birth prevalence of congenital anomalies in the developing world is underestimated due to deficiencies in diagnostic capabilities and lack of reliability of medical records and health statistics. ${ }^{2}$ Occurrence of congenital anomalies varies between different countries ranging from 2 to 10 percent of births. Congenital anomalies are now making a proportionally greater contribution to ill health in childhood. They are a leading cause of perinatal mortality and childhood morbidity and disability in many countries. ${ }^{3,4}$ Every year, an estimated 7.9 million children are born with a serious birth defect of genetic origin. Over 1 million more infants are born with serious birth defects of post-conception origin including those that result from maternal exposure to environmental agents such as alcohol, rubella, syphilis, and iodine deficiency that can harm the developing foetus.'

Serious birth defects can be lethal. It is widely acknowledged that congenital anomalies heavily contribute to infant morbidity and mortality worldwide, with an estimated 9 million infants ( $7 \%$ of all births) born annually having a serious congenital anomaly that result in death or lifelong disability.

An estimated 3.2 million of those who survive without appropriate care may be disabled for life ${ }^{5}$. For those who survive, these disorders can cause lifelong mental, physical, auditory, and visual disabilities that exert a harsh human and economic toll on those affected, their families, and their communities birth defects are a global problem, but their impact on infant and childhood death and disability is particularly severe in middle- and low-income countries ${ }^{5}$.

In Nepal there has not been much studies related to the birth defects. One year review study of congenital anatomical malformation at birth in maternity Hospital in Kathmandu, Nepal showed $0.36 \%$ of the prevalence rate of the congenital anomalies.

The main objectives of the present study is to find out the prevalence of congenital malformation and to know the specific involvement of anatomical structures among babies born at Western Regional Hospital, Pokhara, Nepal.

\section{METHODOLOGY}

This was a hospital-record based, descriptive study of all the live births during a 1 year period from April 2011to March 2012 at the Western Regional Teaching Hospital, Pokhara, Nepal.
Congenital anomalies, congenital malformations, and birth defects are all terms used to describe a structural or functional abnormality present at birth, which might be clinically obvious at the time of birth or diagnosed later on in life. However since this is a record based study, the anomalies included in the study were only cases that were clinically diagnosed at the time of birth by a pediatrician. Anomalous cases were determined and categorized according to organ system by following the International Classification of Diseases (ICD-10).

Detailed data about sex, maturity, weight and congenital defects of all live births including twins and still births with malformation, delivered at Western Regional Hospital during one year period were collected. All relevant information about the congenital defects of these newborns was collected from the main Registration book at the labour room. These defects either major, minor, single, multiple were categorized accordingly to anatomical systems like central nervous, gastrointestinal, cardiovascular, musculoskeletal, genitourinary and others.

\section{RESULTS}

There were total of 10013 deliveries during the period of 1 year. Total number of live birth was 9895 (98.82\%) and still birth $118(1.17 \%)$. Male to female ratio of live birth was 1.19 . Out of 9895 of total live births, congenital anomalies were found amongst $42(0.42 \%)$ children.

\section{Table 1: Distribution of congenital malformations}

\begin{tabular}{|c|l|l|l|}
\hline S. No. & & Frequency & Percentage \\
\hline 1. & Mothers Age Group (Years) & & \\
\hline & $<20$ & 10 & 23.8 \\
\hline & $21-30$ & 31 & 73.8 \\
\hline & $>31$ & 1 & 2.4 \\
\hline 2. & Mother's Blood Group & & \\
\hline & A+ve & 8 & 19.0 \\
\hline & A-ve & 2 & 4.8 \\
\hline & B+ve & 10 & 23.8 \\
\hline & B-ve & 0 & 0.0 \\
\hline & AB+ve & 2 & 4.8 \\
\hline & AB-ve & 1 & 2.4 \\
\hline & O+ve & 19 & 45.2 \\
\hline & O-ve & 0 & 0.0 \\
\hline 3 & Child Birth Weight (Kg) & & \\
\hline & $<2.5$ & 20 & 47.6 \\
\hline & $>2.5$ & 22 & 52.4 \\
\hline
\end{tabular}


Table 1 gives the distribution of birth defects based on the maternal factors and the new born factors. There was no difference in the incidence rate of congenital malformations in male births and female births. Majority of the birth defects cases were seen amongst the mother aged 21-30 years ie $73.8 \%$ as the delivery cases are highest amongst this groups, and then followed by the mothers aged below 20 years of age. Congenital malformations was maximum (42.5\%) with mothers of blood group $\mathrm{O}^{+v e}$, followed by blood group of $\mathrm{B}^{+\mathrm{ve}}$ and $\mathrm{A}^{+\mathrm{ve}}$. No congenital malformations were noted with mothers of blood group of $\mathrm{B}^{-\mathrm{ve}}$ and $\mathrm{O}^{-\mathrm{ve}}$.

There was no significant difference $(p=0.72)$ in distribution of congenital malformations according to birth weight. Out of 42 cases, 20 cases have birth weight $<2.5 \mathrm{k}$.g. and 22 cases have birth weight $>2.5 \mathrm{k} . \mathrm{g}$.

Table 2: Distribution of congenital malformations according to anatomical system. $(n=42)$

\begin{tabular}{|l|l|l|}
\hline Anatomical system & Frequency & Percentage \\
\hline Sense organ system & 3 & 7.1 \\
\hline Nervous system & 5 & 11.9 \\
\hline Genito Urinary system & 6 & 14.3 \\
\hline Musculoskeletal system & 24 & 57.1 \\
\hline Gastrointestinal system & 4 & 9.5 \\
\hline Total & 42 & 100.0 \\
\hline
\end{tabular}

Table 2 summarizes the different anomalies according to body system. Study showed those congenital anomalies were ranging from minor to major, single to multiple systems. Musculoskeletal anomalies accounted for the maximum of $57.1 \%$ followed by genitourinary anomaly $14.3 \%$. Nervous system anomaly was seen in $11.9 \%$, gastrointestinal system anomaly amongst the $9.5 \%$ and $7.1 \%$ in the sense organs.

Table 3: Congenital malformations. $(n=42)$

\begin{tabular}{|l|l|l|}
\hline Congenital defect & Frequency & Percentage \\
\hline Anencephaly & 2 & 4.8 \\
\hline Cleft lip & 1 & 2.4 \\
\hline Cleft Lip, Palate & 1 & 2.4 \\
\hline Cleft palate & 1 & 2.4 \\
\hline Gastroschisis & 1 & 2.4 \\
\hline Haematoma Labia & 1 & 2.4 \\
\hline Hydrocele & 1 & 2.4 \\
\hline
\end{tabular}

\begin{tabular}{|l|l|l|}
\hline Hydrocephalus & 2 & 4.8 \\
\hline Hypospadius & 1 & 2.4 \\
\hline Microtia & 1 & 2.4 \\
\hline Neck Mass & 2 & 4.8 \\
\hline Polydactyl & 3 & 7.1 \\
\hline Polydactyl, Syndactyl & 4 & 9.5 \\
\hline Pre auricular skin tags & 1 & 2.4 \\
\hline Rudimentary genitalia & 1 & 2.4 \\
\hline Single nostril & 1 & 2.4 \\
\hline Spina Bifida & 1 & 2.4 \\
\hline Syndactyl & 10 & 23.8 \\
\hline Talipes equinivarus & 5 & 11.9 \\
\hline Undescended testes & 2 & 4.8 \\
\hline Total & 42 & 100.0 \\
\hline
\end{tabular}

Table 3 shows the subdivisions of the different congenital anomalies. Majority were cases of syndactyl (23.8\%) followed by Talipes equinivarus, Polydactyl and Syndactyl cases.

\section{DISCUSSION}

There were total 9859 deliveries and 10013 births in Western Regional Hospital, Pokhara, in one year. Among them 5390 were males, 4505 were females and 118 were still births.

Incidence of congenital malformations in newborn was $0.42 \%$ among the live birth which was higher than the study conducted in maternity hospital $(0.36 \%)$, Thapathali, Kathmandu. ${ }^{6}$ In both of the studies malformations among the male live births was slightly higher than the female live births.

In our study congenital malformations was higher (73.8\%) with mothers of age group 21-30 years, followed by $\leq 20$ and $\geq$ 31 years. Similar study done in Iran showed that the majority of the mothers are aged between 25.34 years $(61.4 \%)$.

In our study there was no significant difference in distribution of congenital malformations according to birth weight of the newborn. Out of 42 cases, 20 cases have birth weight $<2.5 \mathrm{~kg}$. and 22 cases have birth weight $>2.5 \mathrm{~kg}$ where as study conducted by Malla $\mathrm{BK}^{6}$ showed that congenital malformations is three times more with birth weight $>2.5 \mathrm{~kg}$ than birth weight $<2.5 \mathrm{~kg}$.

In the present study most of the congenital malformations $(57.1 \%)$ were seen in musculoskeletal system, followed by 
Genito-urinary, Nervous, Gastrointestinal and Sense organ system. Similar study by Malla $\mathrm{BK}^{6}$ showed that the most common anatomical system involved in congenital malformations were central nervous system followed by Musculoskeletal, Gastrointestinal, Genitourinary and Sense organ system whereas Arya singhe $\mathrm{L}$ et $\mathrm{al}^{7}$ in their study showed the most common anatomical system involved in congenital malformations were Genito-urinary system followed by Musculoskeletal system.

\section{CONCLUSION}

Incidence rate of congenital anomalies in Western Regional Hospital, Pokhara, in a period of one year was found to be $0.42 \%$. Most of the congenital malformations were seen in musculoskeletal system.

\section{ACKNOWLEDGMENT}

I would like to express my heartfelt thank to Western Regional Hospital, Pokhara administration for kindly allowing me to collect the data for this study.

\section{REFERENCES}

1. Mosby's medical dictionary. 6th ed: Philadelphia:Elsevier health Sciences; 2009. Congenital anomaly.

2. Penchaszadeh VB. Preventing congenital anomalies in developing countries. Public Health Genomics. 2002;5(1):61-69.

3. Druschel C, Hughes JP, Olsen C. Mortality among infants with congenital malformations, New York State, 1983 to 1988. Public health reports. 1996;111(4):359.

4. Al-Gazali, Alwash R, Abdulrazzaq YM. United Arab Emirates: Communities \& Community genetics, Comm Gen 8(2005), 18696.

5. Controlling birth defects; reducing the hidden toll of dying and disabled children in low income countries. (internet) Washington DC(USA), Disease control priorties project. 2008 Dec. (Cited 2010 Sep. 29)

6. Malla B. One year review study of congenital anatomical malformation at birth in Maternity Hospital (Prasutigriha), Thapathali, Kathmandu. Kathmandu Univ Med J (KUMJ). $2007 ; 5: 557-60$

7. Aryasinghe L, Moezzi D, Ansari T, Mathew E, Sharbatti S, Shaikh R. Congenital Anomalies at Birth: A Hospital Based Study in UAE. Journal of Nepal Paediatric Society. 2012;32(2):105-12. 